ORIGINAL RESEARCH ARTICLE

\title{
Empowerment of Adolescent Girls for Sexual and Reproductive Health Care: A Qualitative Study
}

\author{
DOI: $10.29063 / a j r h 2017 / v 21 \mathrm{i} 4.9$
}

\author{
Zainab Alimoradi ${ }^{1}$, Nourossadat Kariman ${ }^{2}$, Masoumeh Simbar ${ }^{3}$, Fazlollah Ahmadi $^{4}$
}

Department of Midwifery, School of Nursing and Midwifery, Qazvin University of Medical Science, Qazvin, Iran ${ }^{1}$; Midwifery and Reproductive Health Research Center, Midwifery and Reproductive Health Department, School of Nursing and Midwifery, Shahid Beheshti University of Medical Science, Tehran, Iran ${ }^{2 *}$; Midwifery and Reproductive Health Research Center, Midwifery and Reproductive Health Department, School of Nursing and Midwifery, Shahid Beheshti University of Medical Science, Tehran, Iran ${ }^{3}$; Department of Nursing, Faculty of Medical Sciences, Tarbiat Modares University, Tehran, $\operatorname{Iran}^{4}$

*For Correspondence: Email: n_kariman@sbmu.ac.ir,n_kariman@yahoo.com; Phone: (+98) 2188202512

\begin{abstract}
Adolescent girls should be empowered to acquire the ability to take care of their sexual and reproductive health. The present study aimed to improve the understanding of the factors affecting the empowerment of Iranian adolescent girls in terms of taking care of their sexual and reproductive health (e.g. pubertal and menstrual health, preventing high risk sexual behaviors, treatment seeking for sexual and reproductive complaints such as dysmenorrhea, genitalia infection). The present qualitative study was performed using conventional content analysis method. Eight key informants were purposively selected and interviewed. Data collection was performed through unstructured and in-depth interviews. The qualitative content was analyzed simultaneously with data collection based on Graneheim and Lundman method using MAXQDA 2010 software. Data analysis led to the emergence of the main theme of empowerment for care with four classes of reinforcing the foundations of sexual and reproductive health, providing services in health system, reinforcing educational institutions, and consolidating the interaction between adolescent and family, as well as thirteen sub-classes. Results of the present study showed the need for inter-sectional interaction and collaboration among authorities of health systems, education systems, and policymaking institutions to achieve a model for empowering adolescent girls via a multi-level and comprehensive approach. (Afr J Reprod Health 2017; 21 [4]: 80-92).
\end{abstract}

Keywords: Adolescent girls, empowerment, self-care, sexual and reproductive health, Iran

\section{Résumé}

Les adolescentes devraient être habilitées à prendre soin de leur santé sexuelle et de la reproduction, car elles connaissent des changements pubertaires et une participation possible à des comportements sexuels à haut risque et acquièrent des capacités de reproduction. La présente étude visait à améliorer la compréhension et la reconnaissance des facteurs affectant l'autonomisation des adolescentes iraniennes en termes de prise en charge de leur santé sexuelle et de la reproduction (p.ex. santé pubertaire et menstruelle, prévention des comportements sexuels à haut risque, traitement des plaintes sexuelles et de la reproduction) tels que la dysménorrhée, l'infection génitale). La présente étude qualitative a été réalisée en utilisant une méthode d'analyse de contenu conventionnelle. Huit informateurs clés ont été délibérément sélectionnés et interviewés. La collecte de données a été réalisée au moyen d'entrevues non structurées et approfondies. Le contenu qualitatif a été analysé simultanément avec la collecte de données basée sur la méthode de Graneheim et Lundman en utilisant le logiciel MAXQDA 2010. L'analyse des données a conduit à l'émergence du thème principal de l'autonomisation des soins avec quatre classes pour renforcer les fondements de la santé sexuelle et de la reproduction, fournir des services dans le système de santé, renforcer les institutions éducatives et consolider l'interaction entre l'adolescent et la famille ainsi que treize sous-classes. Les résultats de la présente étude ont montré la nécessité d'une interaction et d'une collaboration intersectorielles entre les autorités des systèmes de santé, des systèmes éducatifs et des institutions politiques pour parvenir à un modèle d'autonomisation des adolescentes par une approche multiniveau et globale. (Afr J Reprod Health 2017; 21[4]: 80-92).

Mots-clés: Adolescentes, autonomisation, autosoins, santé sexuelle et de la reproduction, Iran 


\section{Introduction}

Adolescence is the time for comprehensive and profound changes and the period of puberty as well as physical, cognitive, and social maturity ${ }^{1}$. In girls, this period as a specific stage of life requires special attention and consideration ${ }^{2}$ because the beginning of adolescence is associated, on the one hand, with the onset of puberty and menstruation and, on the other hand, with the discovery of sexual desires ${ }^{3,4}$. Misconceptions and wrong health behaviors in the process of menstruation and puberty endanger the health of girls ${ }^{5}$. Moreover, due to the discovery of sexual desires, involvement in high-risk sexual behaviors might occur for many of the adolescent girls and lead to sexual intercourse, unwanted pregnancy, or sexually transmitted diseases ${ }^{3}$. All of these can affect this period of adolescents' lives and have huge ramifications on social and public health ${ }^{6}$. According to the results of a review, adolescents might get involved in high-risk sexual behaviors due to various reasons including inadequate knowledge, wrong beliefs in sexual performance, wrong attitude toward high-risk sexual intercourse and behaviors, and lack of refusal skills ${ }^{7}$. Thus, due to the pubertal and menstrual changes as well as the probability of getting involved in high-risk sexual behaviors, adolescent girls should acquire the ability to take care of their sexual and reproductive health. In this case they should acquire the ability to take care for their pubertal and menstrual health ${ }^{8}$, understand the ways to prevent high risk sexual behaviors, reduce cases of high risk sexual encounters ${ }^{9}$, and seek treatment for sexual and reproductive complaints such as dysmenorrhea, genitalia infection, problems encountered after sexual relations ${ }^{10}$.

Today, empowerment is one of the most important concepts in health promotion and health-related quality of life $^{11}$. According to WHO, empowerment is the core of health promotion that enables people to gain more control over the decisions and actions affecting their health ${ }^{12,13}$. The outcomes of empowerment include positive self-confidence, ability to achieve the objective, having a sense of control over life and change processes, as well as sense of future expectation. Empowerment means helping individuals in such a way that they can achieve the ability to change ${ }^{14}$. Different models have been introduced for empowering adolescents. In the empowerment holosphere model, achieving the goals of empowering individuals requires the definition of the strategies at several levels, including personal empowerment, development of small groups (intra-group empowerment), organizing the society (inter-group empowerment), and interorganizational actions (coalition, advocacy, and political measures $)^{15}$. The adolescent empowerment cycle model is focused on three areas of adolescent participation in meaningful activities, providing opportunities for skill development, and positive reinforcement and recognition from adults ${ }^{16}$. In the youth development and empowerment (YD\&E) model, in addition to the above-mentioned issues, there is an emphasis on the importance of using adolescents as leaders ${ }^{17}$. In the transactional partnering model, the feature of power sharing between adolescents and adults is more than the one in the other models; further, this model also suggests the development of the social activities led by adolescents, which provides adolescents with leadership opportunities and situations ${ }^{18}$. The emphasis of the empowerment education model is on the skill and knowledge development that supports adolescents' attempts for social activity and change, and links the personal empowerment to social organization ${ }^{19}$.

Adolescents' empowerment programs in Iran have been investigated in some studies, which have used the individual- and familycentered empowerment models to design the interventions. The individual empowerment models are used to promote self-management and improve the quality of life of adolescents with major thalassemia ${ }^{20}$, as well as to prevent the high-risk behaviors in labor and street adolescents $^{21}$. However, the family-centered empowerment model is used to prevent the iron deficiency anemia in adolescent girls ${ }^{22}$, as well as to improve the quality of life of mothers of the adolescents with iron deficiency anemia ${ }^{23}$. As for the empowerment for self-care, Heidari 
used an educational program based empowerment model with three steps of threat perception, problem solving, and assessment to promote the self-efficacy, self-esteem, and $\mathrm{HbA}_{1 \mathrm{C}}$ control in adolescents with type-1 diabetes ${ }^{24}$.

No research has been conducted on the empowerment for reproductive and sexual selfcare in Iran. The existing studies, have investigated the problems of pubertal and menstrual health as well as the sexual health, merely with a health education approach. They have not taken into consideration the requirements of the empowerment of girls for reproductive and sexual self-care. Thus, such training might not reflect the actual needs of this group $^{3}$. Empowerment training should consider helping the participants discover the reality of their experiences and perceive how to act in order to facilitate changes ${ }^{25}$.

With respect to the importance of empowering adolescent girls for sexual and reproductive self-care, the present study was conducted with a qualitative approach to identify and explain the factors affecting the adolescent girls' empowerment for sexual and reproductive self-care. Improving the perception and knowledge of the factors affecting the adolescent girls' empowerment would facilitate designing and providing more appropriate and sensitive services and training. Results of the present research would help health policy makers, sexual and reproductive health service providers, and education system authorities find out how to help adolescent girls' sexual growth and development process and lead them to proper and desirable self-care.

\section{Methods}

The present study was conducted using conventional content analysis method. Content analysis is a research method for generating repeatable and valid results from the relevant data, and is aimed to provide the knowledge and new vision as well as represent facts and a guide for action $^{26}$.

Purposive sampling was used in order to achieve the maximum diversity in choosing the participants from December 2015 through June 2016 in Karaj and Tehran. The participants in this study were eight key informants who had experience with sexual and reproductive health of adolescent girls. Data collection was performed using unstructured in-depth interviews with the participants including one sexual health expert, one reproductive health expert, one school counselor, one educational teacher, three mothers and a father having an adolescent girl. Different key informants were interviewed to reach maximum variation and data saturation. The interviews were performed in a suitable place, in which the participants felt comfortable. Before performing the interviews, the participants' consent for participation was verbally obtained by explaining the research objective. All of the interviews were recorded with prior arrangement and consent of the participants.

The interview began with a question on "what is the meaning of adolescent girls' sexual reproductive self-care?" after participants' answer to this question and insuring that participants had good understanding of the concept, they were asked the main question of "How can adolescent girls take care of their sexual and reproductive health?" During the interview, in accordance with the given responses, some clarifying and exploratory questions were used to deepen the interview and obtain more comprehensive information. Duration of the interviews varied between 20 and $80 \mathrm{~min}$, depending on the participants' desire.

Data analysis was performed simultaneously with data collection and according to the steps proposed by Graneheim and Lundman $^{27}$; accordingly, the word-by-word typing of the interviews was done. MAXQDA 2010 software was used for data storage, retrieval, and analysis. In order to achieve overall data perception, the transcribed interviews were read several times by the researcher before starting the encoding. The semantic units were specified after reviewing the interviews' transcriptions and by determining the main sentences and concepts in each line or paragraph. The summarized semantic units were 
Table1: Results of Analysis of the Interviews

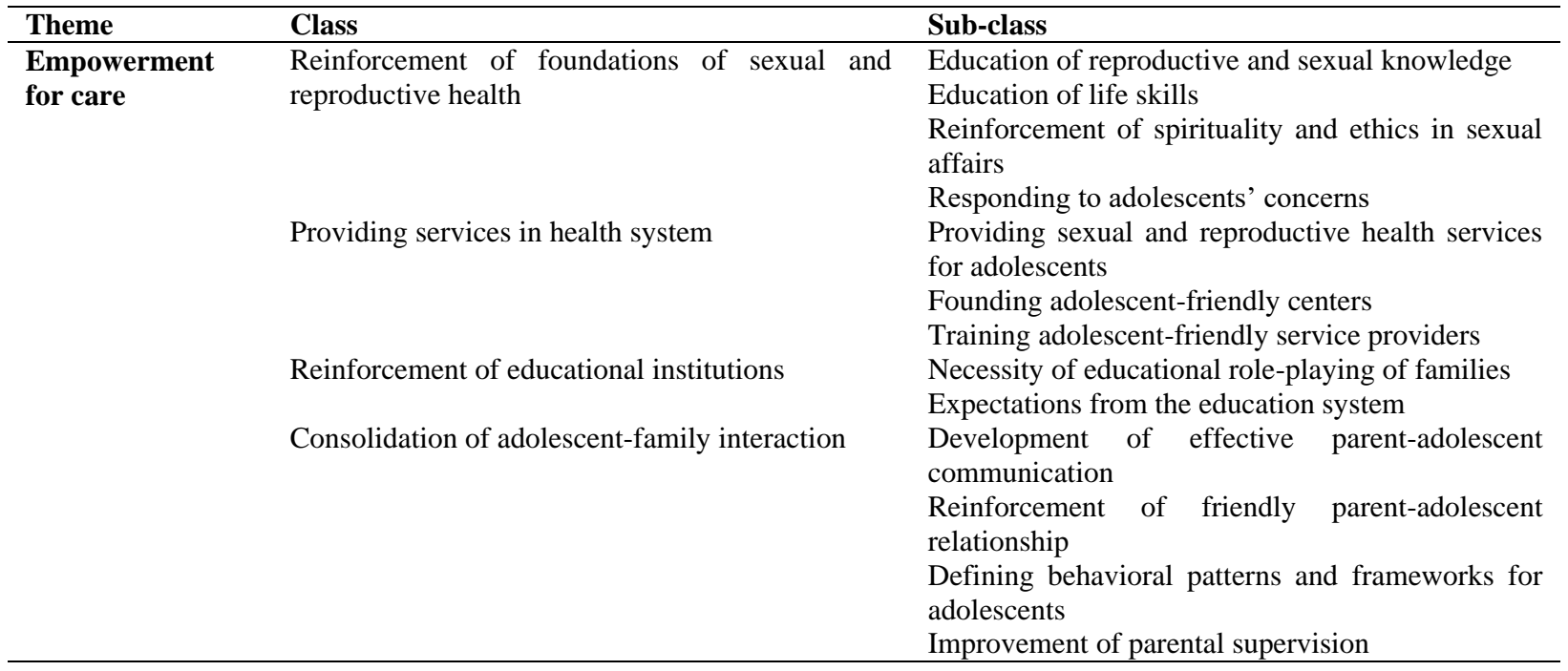

named using the main codes. Regarding the similarity of the concepts associated with a single phenomenon, the main codes were classified as the sub-classes and classes. Finally, based on the latent concepts in the classes, the theme was extracted.

Data credibility was achieved through long-term working with the participants, member checking, and peer checking. For the member checking, transcription of the interviews along with the extracted codes was given to two of the participants who were selected randomly, and the agreement of their opinion with that of the researcher was evaluated. Peer checking was performed by giving the interviews' transcription along with the codes and classes extracted from the interviews to the members of the research team. Further, the participants were selected with maximum diversity in terms of the relation with the sexual and reproductive problems of the adolescent girls in order to increase the transferability of the findings. Moreover, the external auditing and code-recode methods were used during data analysis to increase the data dependability.

\section{Ethical Consideration}

This article is a part of a qualitative study for explaining the concept of the adolescent girls' sexual and reproductive self-care as well as developing and psychometrically analyzing the instrument, which was established with the code of SBMU2.REC.1394.66 in Ethics Committee of Shahid Beheshti University of Medical Sciences. Prior to initiating the study, agreement of the relevant authorities was achieved. At the beginning of the interviews, the participants were provided with some explanations on the research objective, interview method, data confidentiality, and their freedom in entering or leaving the study, and then their verbal consent for participation in the research was obtained. The time and place of the interviews were also coordinated with the participants' consent.

\section{Findings}

The participants of the present study were eight key informants including one sexual health expert experienced in clinical and research activities on the adolescents' sexual health, one reproductive health expert experienced in research on adolescent girls' pubertal and menstrual health, one school counselor with Master's degree in psychology, 15 years of experience in the education system, and owning a counseling office, one educational teacher with an associate degree and 27 years of experience in vocational schools, three mothers (43 years old, associate degree, teacher; 38 and 40 years old, high school diploma, housewives), and one 
father (42 years old, high school diploma, selfemployed).

Data analysis led to the emergence of the main theme of the empowerment for care with 13 subclasses and 4 classes of reinforcement of the foundations of sexual and reproductive health, providing services in the health system, reinforcement of the educational institutions, and consolidation of the interactions between adolescents and family. A summary of the results is presented in Table (1).

\section{Reinforcement of foundations of sexual and reproductive health}

Sexual and reproductive knowledge, life skills, spirituality and ethics, and responding to adolescents' concerns were the issues noted by most of the participants as the factors influencing adolescents' sexual and reproductive health. Most of the participants believed that reinforcing these factors via appropriate training is essential to achieve the objective of desirable reproductive and sexual self-care in adolescent girls. The perceptions of participants are reflected in following quotations:

"I was invited as the lecturer for education in a high school ... The girls asked so many questions on menstruation and sexual issues that revealed they didn't have proper information, and content of their questions revealed that what they knew was also wrong" (Participant 7, reproductive health expert).

"Many teenage girls are afraid of refusing their boyfriend's request on having sexual relations. They are afraid of being abandoned by their boyfriends. The problem is that they don't know life skills, they lack critical thinking to think of the consequences of their decisions, they don't respect their own beliefs, so that they can't refuse such requests" (Participant 8, sexual health expert).

"Adolescents have some questions, for example, about their body's anatomy ... When they can't find answers to these questions, it gradually worries them" (Participant 5, school counselor).
"Those girls who say their prayers and care about hijab are less likely to look for boyfriends ... I'm afraid of those who don't have high religious tendencies ... Sometimes, when I talk to them about moral considerations and tell them that, regardless of religious beliefs, they should not acquiesce to everything due to their own value and self-esteem, they accept it more easily" (Participant 6, teacher).

\section{Providing services in health system}

The need for receiving health services, especially sexual and reproductive ones, was presented as another necessity to empower adolescents for self-care.

"Self-care doesn't mean that we can put the ball in their (adolescents) court without providing any services for them ... Beside education, this generation needs to be provided with services" (Participant 8, sexual health expert).

However, providing health services for adolescents should be based on specific standards and features. According to the participants' viewpoints, the health services for adolescents should be provided in the adolescent-friendly centers by providers who have been trained to work with adolescents.

"Sometimes, some of the girls have problems and they come and talk to me about them, for example about the genital infection ... They are embarrassed to talk to anyone about their problem, they don't know where to go ... It would be very good if there were some special places for them to refer" (Participant 6, educational affairs instructor).

"Once an adolescent girl who had become pregnant after a sexual intercourse with her boyfriend referred to me ... When she came to me, she was eight-month pregnant ... She hadn't gone anywhere for caring because she didn't know to whom she must refer, and also was afraid of being mishandled and turned over to the police" (Participant 7, reproductive health expert). 
Training of health service providers is an important issue in providing services for adolescents. In the current conditions, due to the lack of infrastructures of centers providing the adolescent-friendly service, this group should not be deprived of health services.

"There is not yet an active sexual health clinic, especially for adolescents, but we have counselors, gynecologists, infectious disease specialists, and so on ... But the problem is that adolescents should be treated in such a way that they could refer to such centers ... In our own center, when a teenager refers to us, she could pay the half-price, then we give her a code so that she could remain unknown and avoid being judged when referring to the laboratory" (Participant 8, sexual health expert).

Thus, training health service providers to provide adolescent-friendly services can be brought into consideration as a more appropriate and available solution to promote the adolescents' empowerment for reproductive and sexual health care.

\section{Reinforcing educational institutions}

Approximately all the participants noted that two institutions of family and school have the main responsibility of educating adolescents; therefore, these institutions should be reinforced to provide appropriate sexual and reproductive training, commensurate with the adolescent's growth and development stages. Family as the first educational institution must be taken into consideration and acquire the necessary preparation for its educational role. The participants noted that mothers should play an important role in providing education on sexual and reproductive issues to their own adolescent girls; however, the problem is lack of sufficient knowledge as well as disregard for the responsibility of educating the children. Thus, mothers must get prepared for playing their educational role via receiving appropriate training about the importance of proper and appropriate educational content as well as method of presentation.
"I hold educational sessions for mothers at schools about nature of puberty, key points on menstrual health, different aspects of self-care during puberty such as nutrition, exercise, sexual risk taking... And tell them you should talk to your daughters about menstruation, puberty, and self-care in the society' ... Some of the mothers say 'Would you please talk to them at school yourself because we are embarrassed to talk?' ... and some others object and say 'talking about these things would make them cheeky" "(Participant 5, school counselor).

"During the training, when I told the adolescents that they should wash themselves after using lavatory, they said that their mothers have told them this would cause infections ... As long as mothers lack proper information on the sexual and reproductive issues, they can hardly be expected to be a good guide for their children" (Participant 7, reproductive health expert).

Schools as the second educational institution are also of great importance. People spend a long time at schools, from the onset up to the end of their adolescence, and have numerous interactions with their peers, teachers, and instructors. The participants' experiences indicated that under the current conditions, there is no appropriate training on sexual and reproductive issues as well as life skills at schools, and the few available cases lack the required sufficiency. Most of the participants noted that the education institution, as the principal institution in making decisions on designing and providing the educational content for schools as well as training teachers as the providers of raining, should pay more attention to adolescents' sexual and reproductive training and take the necessary actions.

"In the books that are newly used at schools, the issue of puberty and menstruation at the age of 15 is discussed, while most of the girls' experience menstruation at the end of elementary school without receiving appropriate training, so they only hear some things about it from their friends that are mostly wrong" (Participant 8, sexual health expert). 
"The books that are currently taught at schools don't sufficiently treat high-risk behaviors, especially AIDS ... As for the contraceptive methods, they only shortly mention condoms, but not so much that students can understand what is a condom, and how and when it can be used" (Participant 5, school counselor).

\section{Consolidation of adolescent-family interaction}

All the participants believed that families play an important role in forming sexual and reproductive behaviors of adolescents. In addition to playing their own educational role, families can help adolescents in their sexual and reproductive self-care using the processes such as developing effective parent-child communication, reinforcing friendly parentchild relationships, defining frameworks and behavioral models for adolescents, and improving parental supervision.

Effective parent-child communication, as a way for transferring data, concepts, and values of the family, is of great importance. The participants' experiences showed that in the current conditions, many of the mothers cannot easily talk with their adolescent girls about the issues of puberty and menstruation, as well as the sexual problems, which leads to the insufficiency of their knowledge about sexual and reproductive health issues.

"Many mothers think that talking about such issues would make the child cheeky, and some others are embarrassed to talk about them or even consider these issues as taboo (Participant 5 , school counselor).

"When my daughter heard our neighbors were going to go to a circumcision party, she asked me about the meaning of circumcision. I found out that she still didn't know about the difference between boys and girls, but I was embarrassed to explain the difference of boys and girls for my daughter" (Participant 1, a 40year-old mother with high school diploma, a housewife).
Reinforcement of the parent-adolescent friendly relationship was another issue noted by the participants. The presence of such friendly relationships can attract the trust and indicate the family's support for the adolescent. Having sense of support and trust from the family was discussed as a factor for the adolescent's more tendency toward the family as well as reduced effect of the pressure of peers on decisions of adolescents.

"At home, we don't take it too hard on her in order to have a friendly atmosphere so that she can feel comfortable and tell us her problem ... If we go ahead with her step by step, then it will be easier to make compromise with her and obtain her trust" (Participant 2, a 38-year-old mother with high school diploma, a housewife).

"To increase my daughter's self-esteem, we use her opinions at home for making decisions ... Sometimes, we give her the monthly salary and let her make plan for it; in this way, not only her self-esteem is increased, but she also knows how valuable she is for us" (Participant 3, a 43-yearold mother with associate degree, a teacher)

Families should delineate the behavioral frameworks and relationship expected from adolescents; accordingly, having the specified behavioral models and knowing the red lines, adolescents can make better decisions about their behaviors.

"Once I found from the tone of my daughter's voice that her friends have boyfriends ... When I was talking to her, I told her that it is religiously wrong and such a thing shouldn't occur ... Everything has a framework, and for the relationship between the girls and boys, this framework should be also regarded as well" (Participant 4, a 42-year-old father with high school diploma, self-employed).

Improvement of the parental control was expressed as another important factor to reduce the possibility of the adolescents' risk-taking. Supervision and control help the parents identify the possible risks which adolescents might face, and help their children through appropriate ways 
to take care of themselves from the probable harms.

"Anyway, I control her computer and cell phone secretly without being seen to take a reasonable action if there is something improper" (Participant 4, a 42-year-old father with high school diploma, self-employed).

\section{Discussion}

Results of the present study showed that the empowerment of adolescent girls for achieving the desirable sexual and reproductive self-care requires the reinforcement of sexual and reproductive knowledge, life skills, spirituality and ethics, along with consolidation of the family-adolescent interaction, providing sexual and reproductive health services with an adolescent-friendly approach, and reinforcement of the educational role of family and school. The components required for empowering the adolescent girls for sexual and reproductive selfcare emerging in the present study are considerably consistent with the empowerment holosphere model. The present study discussed the need for having strategies for individual empowerment through educating knowledge, skills, and ethics, developing family processes (for adolescent's empowerment through family), reinforcing educational institutions of family and school, and providing health services, the last two cases of which require actions for organizing the society as well as interorganizational actions. According to Peterson, the best concept in explaining the sexual empowerment is the clarification of the point that sexual empowerment is a continuous and multidimensional construct ${ }^{28}$. Further, Berkeley, in expressing the strategies for promoting adolescents' sexual health, points out the necessity of having a holistic approach to create effective changes at cultural, socioeconomic, and service providing levels ${ }^{6}$.

The need for reinforcing the sexual and reproductive knowledge, spirituality, and ethics was one of the findings of this study that required designing programs for empowerment at the individual level; besides, training and reinforcing life skills in an adolescent would help adjust the interactions in her individual and social relationships. Empowerment at the individual level requires eliminating personal inabilities and forming sense of personal power and self-efficacy. At the interpersonal level, ability means having the capacity required for influencing others ${ }^{29}$. To achieve this objective, it is necessary to develop the skills like problemsolving, self-efficacy, self-control, and selfesteem, since they enable people to have a more controlled behavior in dealing with different phenomena ${ }^{30}$. Based on the UNICEF statement, if knowledge, attitude, and skills are not taken into consideration interactively in the empowerment of the individuals in the society, the expected result that is the reduction of the high-risk behaviors will not be obtained ${ }^{31}$. In the adolescents' sexual empowerment program, Grose took into account the sexual educations on the health, sexual, reproductive, and contraceptive issues alongside with the sexual identity (individuals' attitude toward the sexual roles based on the cultural context of the society). Executing these school-based sexual educational programs showed the positive relationship between some sexual empowerment components including the sexual identity, sexual and reproductive knowledge, and contraceptive beliefs $^{32}$.

Consolidation of the interaction between family and adolescent was another finding of this research, indicating that the processes such as developing effective parent-adolescent communication, reinforcing friendly parentchild relationship, defining behavioral models and frameworks for adolescents, and improving parental control could play effective roles in the promotion of sexual and reproductive self-care in adolescent girls. Therefore, it is worth to be noted that the family-centered empowerment should be taken into consideration as another level of empowerment in the sexual and reproductive self-care of the adolescent girls. The family-centered empowerment has been perceived based on the effectiveness of the family's role in the motivational, psychological, knowledge, attitude, and threat aspects ${ }^{33}$. Since various family factors including parenting styles, parent-adolescent relationship, parental 
control $^{34-39}$, dependence on family and enjoying the trust and support of the family ${ }^{40}$, and parentadolescent communication $^{41}$ affect the formation of adolescent's sexual behaviors, the familycentered empowerment models can be used with a focus on the improvement of the family processes such as parenting styles, parentadolescent communication, and parental control in order to influence the sexual behavior of adolescents. These findings can be proved by, for instance, the positive effect of the relationship improvement program on the quality of parent-child relationship of the adolescent girls in the mother-headed singleparent families in the study conducted by Zareh $^{42}$, as well as the parent-adolescent improvement subsequent to providing the Parent-Adolescent Communication Toolkit educational program in Toombs' study ${ }^{43}$. Furthermore, in addition to the family, the intragroup empowerment can also be executed by the peers group. The results of Hsu's study showed that empowerment based on the empowerment education model and through the peers group's interventions can positively affect the sexual decisions of adolescent girls ${ }^{3}$. Further, in the program of empowering and supporting the adolescents exposed to the risk of drug abuse, Moody used a multi-level approach including skills training, providing support by mentors, growing a positive peer culture, and putting adolescents in the position of the leadership of social services. The results of this research represented the self-esteem improvement, social skills learning, mentor support, positive peer bonding, and school attachment ${ }^{44}$.

Reinforcement of the educational role of family and school was another finding of this study, indicating the importance of the educational role of family, especially mothers, in the sexual and reproductive training of the adolescent girls as well as the role of the school in providing the appropriate and expedient training at various ages. In many studies, families, especially mothers, play important roles in training and transferring the health information and behaviors to the adolescent girls for having a healthy transition from the adolescence period ${ }^{45,46}$. However, results of the present study showed that many of the mothers could not easily and comfortably talk with their daughters about sexual and reproductive issues. Shame and embarrassment, lack of information about different aspects of puberty, unawareness and lack of knowledge about their crucial role in transferring the information to their girls and unawareness about how and when to communicate about these issues with their girls were the most important reasons that should be taken into consideration. Anousheh et al. found that the major reason for the adolescents' lack of proper knowledge and information on the physical and psychological changes during the pubertal period, especially the girls, was the mothers' insufficient recognition and knowledge of the puberty as well as their failure in preparing and training the girls ${ }^{47}$. According to the dominant culture and traditions in Iran, the embarrassment and prudency of the parents to learning the pubertal and adolescence-related issues is obvious; further, the parents' knowledge might not be at such a level that they can provide correct and appropriate information for their children ${ }^{48}$. Therefore, although one of the appropriate and effective methods for transferring the training to the girls is through the family, especially mothers ${ }^{49}$, they must acquire the ability to perform such tasks. Moreover, schools are another important field for performing the health promotion programs for the youth and adolescents ${ }^{50}$. Integrating any kind of program for the adolescents and youth in the school curriculum would be possible, effective, and cost-effective. Implementing the program of empowering adolescents with life skills through mental health program of schools in India ${ }^{51}$, educational intervention for empowering the students to prevent smoking in $\operatorname{Iran}^{29}$, and sexual and pubertal health education program in the elementary schools in Australia ${ }^{52}$ are some examples of the programs that have used the potential of schools for adolescents' empowerment.

The need for providing adolescentfriendly services was another finding of the present study, emphasizing the importance of providing adolescent-friendly services along 
with training adolescents. It should be noted that today's young generation is faced with more complicated challenges in relation with growth, development, and health compared to the parents; nevertheless, most of these challenges can be prevented by providing the access to the primary healthcare for adolescents and the youth $^{53}$. The reproductive health service providers around the world believe that the adolescent-friendly services are essential and necessary for the young individuals' sufficient access to the reproductive health services ${ }^{54}$. To achieve such a goal, decision-makers of the health affairs can define new structures with regard to the existing cultural, social, and economic grounds or apply modifications and changes to the currently existing spaces ${ }^{6}$. Thus, providing the adolescent-friendly services requires designing the infrastructures commensurate with the culture and conditions of the society as well as training the human force for providing the appropriate services. In this regard, it is necessary to attract the protection and support of the decision-makers and authorities of health affairs for the practical implementation of these structures. Therefore, it should be said that empowerment in the political and social dimensions is not independent and separated from other aspects, and a political action requires the active participation and cooperation of the members to achieve the objective of redistributing the resources or appropriate decision-making for certain groups $^{19}$.

\section{Limitations}

Studies with qualitative nature are less generalizable; this constraint also applies to the present study. As the adolescent girls in range of 14 to 19 -year olds were in focus of this study, so the results of this study cannot be generalized to the adolescent boys and girls of other age groups and the adolescent girls from different cultural and social backgrounds. In this study, the opinions of the experts in the adolescents' sexual and reproductive health as well as the key individuals affecting the formation of the adolescents' reproductive behaviors, including fathers, mothers, and school mentors and counselors, were used. It is evident that the use of opinions of the adolescents during compilation, implementation, and assessment of the empowerment programs can enrich the content of such programs.

\section{Conclusion}

With a qualitative approach and based on the adolescents' conditions in the currently existing cultural context in Iran, this study showed that reinforcement of the sexual and reproductive knowledge, life skills, spirituality and ethics, along with consolidation of the interaction between family and adolescent, providing sexual and reproductive health services with adolescent-friendly approach, and reinforcing the educational role of family and school as the educational institutions can play important roles in the adolescent girls' sexual empowerment. Further, results of this study indicated the need for interaction and cooperation between the authorities of the health systems, education systems, and policy-making institutions to achieve a model for empowering the adolescent girls with a multi-level and comprehensive approach.

\section{Funding}

This study was funded by Shahid Beheshti University of Medical Science.

\section{Conflict of Interest}

The authors declare that they have no conflict of interest.

\section{Ethical Approval}

All procedures performed in studies involving human participants were in accordance with the ethical standards of the institutional research committee and with the 1964 Helsinki declaration and its later amendments or comparable ethical standards. 


\section{Informed Consent}

Informed consent was obtained from all individual participants included in the study.

\section{Contribution of Authors}

Z. Alimoradi and N. Kariman equally contributed to the conception and design of the research; F.Ahmadi and M.Simbar contributed in designing the research; Z.Aimoradi collected the data; all authors contributed to analysis of the data; Z.Alimoradi and N.Kariman contributed to the interpretation of the data; Z.Alimoradi drafted the manuscript. All authors critically revised the manuscript, agree to be fully accountable for ensuring the integrity and accuracy of the work, and read and approved the final manuscript.

\section{References}

1. Blakemore SJ, Burnett $S$ and Dahl RE. The role of puberty in the developing adolescent brain Human brain mapping. 2010; 31: 926-33.

2. Tegegne TK and Sisay MM. Menstrual hygiene management and school absenteeism among female adolescent students in Northeast Ethiopia. BMC Public Health. 2014; 14: 1118.

3. Hsu HY, Lien YF, Lou JH, Chen SH and Wang RH Exploring the effect of sexual empowerment on sexual decision making in female adolescents. Journal of Nursing Research. 2010; 18: 44-52.

4. Sommer M .Where the education system and women's bodies collide: The social and health impact of girls' experiences of menstruation and schooling in Tanzania. Journal of adolescence. 2010; 33: 521-9.

5. Oche M, Umar A, Gana G and Ango J. Menstrual health: the unmet needs of adolescent girls in Sokoto, Nigeria. Scientific Research and Essays. 2012; 7: 410-8.

6. Berkeley D and Ross D. Strategies for improving the sexual health of young people. Culture, health \& sexuality. 2003; 5: 71-86.

7. Bahrami N, Simbar M and Soleimani MA. Sexual health challenges of adolescents in Iran: A review article Journal of School of Public Health and Institute of Public Health Research 2013; 10: 116.

8. Adika V, Ayinde M and Jack-Ide I. Self care practices of menstrual hygiene among adolescents school going girls in Amassoma Community, Bayelsa State. International Journal of Nursing and Midwifery. 2013; 5: 99-105.
9. WHO. The sexual and reproductive health of young adolescents in developing countries: Reviewing the evidence, identifying research gaps and moving the agenda. Report of a WHO technical consultation Geneva4-5 November 2010, p. 17.

10. Moreira E, Brock G, Glasser DB, Nicolosi A, Laumann EO, Paik A, Wang $\mathrm{T}$ and Gingell C. Helpseeking behaviour for sexual problems: The global study of sexual attitudes and behaviors. International journal of clinical practice. 2005; 59: 6-16.

11. Tengland PA. Empowerment: a goal or a means for health promotion? Med Health Care Philos. 2007; 10: 197-207.

12. Laverack G and Labonte R. Health promotion in action: from local to global empowerment. Palgrave Macmillan, 2008.

13. Haggart $\mathrm{M}$ and Carey P. Community health promotion: Challenge for practice. London, Royal College of Nursing Pub. 2000.

14. Speer PW, Jackson CB and Peterson NA. The relationship between social cohesion and empowerment :Support and new implications for theory. Health education \& behavior. 2001; 28: 716-32.

15. Labonte R. Health promotion and empowerment: Reflections on professional practice. In: Black JM, Furney SR, Graf HM and Nolte AE, (eds.). Philosophical foundations of health education. San Francisco: John Wiley \& Sons, 2010.

16. Chinman MJ and Linney JA. Toward a model of adolescent empowerment: Theoretical and empirical evidence. Journal of Primary Prevention. 1998; 18: 393-413.

17. Kim S, Crutchfield C, Williams C and Hepler N. Toward a new paradigm in substance abuse and other problem behavior prevention for youth: Youth development and empowerment approach. Journal of drug education. 1998; 28: 1-17.

18. Cargo M, Grams GD, Ottoson JM, Ward P and Green LW. Empowerment as fostering positive youth development and citizenship. American Journal of Health Behavior. 2003; 27: S66-S79.

19. Jennings LB, Parra-Medina DM, Hilfinger-Messias DK and McLoughlin K. Toward a critical social theory of youth empowerment. Journal of Community Practice. 2006; 14: 31-55.

20. Razzazan N, Ravanipour M, Gharibi T, Motamed N and Zarei A. Effect of self-management empowering model on the quality of life in adolescents and youths with major thalassemia Quarterly journal of nursing education (jne). 2014; 3: 48-59.

21. Ayatmehr F, Khaleghi M, Mohammadkhani S and Ghiasi H. The Efficacy of Education of Adolescent Empowerment in Prevention of Risky Behaviors in Child Labor. Quarterly Journal of Social Work. 2015; 4: 16-23.

22. Elhani F, Niknami S, Kimiagar SM, Kazemnejad A and Heydarnia AR. Empowerment of a family- 
oriented pattern and its effects on prevention of iron deficiency anemia in adolescent girls. Bimonthly Pejouhandeh. 2003; 8: 283-90.

23. Roshan FSN, Navipor $\mathrm{H}$ and Alhani F. Effect of Family-Centered Empowerment Model (FCEM) on quality of life of mothers having teenagers with iron deficiency anemia. Quarterly journal of nursing education (jne). 2003; 3: 28-40.

24. Heidari M, Alhani F, Kazemnejad A, Tol A and Moezi F. Assessing the Effect of Educational Program Based on Empowerment Model on HbA1C among Adolescents with Type 1 Diabetes. Journal of Health System Research 2013; 8: 1376-84.

25. Rindner EC. Using Freirean empowerment for health education with adolescents in primary, secondary, and tertiary psychiatric settings. Journal of Child and Adolescent Psychiatric Nursing. 2004; 17: 78-84.

26. Elo $S$ and Kyngäs $H$. The qualitative content analysis process. Journal of advanced nursing. 2008; 62: $107-15$

27. Graneheim UH and Lundman B .Qualitative content analysis in nursing research: concepts, procedures and measures to achieve trustworthiness. Nurse education today. 2004; 24: 105-12.

28. Peterson ZD. What is sexual empowerment? A multidimensional and process-oriented approach to adolescent girls' sexual empowerment. Sex Roles. 2010; 62: 307-13.

29. Solhi M, Abasi H, Hazavehei MM and Roshanaei G. Effect of educational intervention on empowerment of high school student in prevention of smoking. Razi Journal of Medical Sciences. 2014.63-52:21;

30. Gordon JR. A diagnostic approach to organizational behavior. Allyn \& Bacon, 1993.

31. Rootman I. Evaluation in health promotion: principles and perspectives. WHO Regional Office Europe, 2001.

32. Grose RG, Grabe S and Kohfeldt D. Sexual Education, Gender Ideology, and Youth Sexual Empowerment. The Journal of Sex Research. 2014; 51: 742-53.

33. Masoodi R, Alhani F, Moghadassi J and Ghorbani M. The effect of family-centered empowerment model on skill, attitude, and knowledge of multiple sclerosis caregivers. Journal of Birjand University of Medical Sciences. 2010; 17: 87-97.

34. Huebner AJ and Howell LW. Examining the Relationship Between Adolescent Sexual RiskTaking and Perceptions of Monitoring, Communication, and Parenting Styles. Journal of Adolescent Health. 2003; 33: 71-8.

35. Madkour AS, Farhat T, Halpern CT, Godeau E and Gabhainn SN. Early adolescent sexual initiation as a problem behavior: a comparative study of five nations. The Journal of adolescent health : official publication of the Society for Adolescent Medicine. 2010; 47: 389-98.
36. Wight D, Williamson L and Henderson M. Parental influences on young people's sexual behaviour: A longitudinal analysis. The Journal of adolescent health : official publication of the Society for Adolescent Medicine. 2006; 29: 47394.

37. Wamoyi J and Wight D. 'Mum never loved me.' How structural factors influence adolescent sexual and reproductive health through parent-child connectedness: a qualitative study in rural Tanzania. African journal of AIDS research : AJAR. 2014; 13: 169-78.

38. Kajula LJ, Sheon N, De Vries H, Kaaya SF and Aarø LE. Dynamics of parent-adolescent communication on sexual health and HIV/AIDS in Tanzania. AIDS and Behavior. 2014; 18: 6974.

39. Schouten BC, Putte Bvd, Pasmans M and Meeuwesen L. Parent-adolescent communication about sexuality: The role of adolescents' beliefs, subjective norm and perceived behavioral control. Patient Education and Counseling. 2007; 66: 75-83.

40. Borawski EA, Ievers-Landis CE, Lovegreen $\mathrm{LD}$ and Trapl ES. Parental monitoring, negotiated unsupervised time, and parental trust: The role of perceived parenting practices in adolescent health risk behaviors. Journal of Adolescent Health. 2003; 33: 60-70.

41. Hutchinson MK and Cooney TM. Patterns of parentteen sexual risk communication: Implications for intervention. Family relations. 1998: 185-94.

42. Zare Bahramabadi M, Zahrakar K, Salehian Broojerdi $\mathrm{H}$ and Mohammadifar M. The Effectiveness of Relationship Enhancement Program on Quality of Parent-Child Relationship in Mothers who are Heads of Household in Single-Parent Families. 2. 2013; 5: 14-24.

43. Toombs E. Evaluating the Parent-Adolescent Communication Toolkit: Usability, measure assessment and preliminary content effectiveness. Dalhousie University, Halifax, Nova Scotia, 2014.

44. Moody KA, Childs JC and Sepples SB. Intervening with at-risk youth: evaluation of the youth empowerment and support program. Pediatric nursing. 2003; 29: 263.

45. Golchin NA, Hamzehgardeshi Z, Fakhri $M$ and Hamzehgardeshi L. The experience of puberty in Iranian adolescent girls: a qualitative content analysis. BMC Public Health. 2012; 12: 698.

46. Mosavi SA, Babazadeh R, Najmabadi KM and Shariati M. Assessing Iranian adolescent girls' needs for sexual and reproductive health information. The Journal of adolescent health : official publication of the Society for Adolescent Medicine. 2014; 55: 107-13.

47. Anoosheh M, Niknami S, Tavakoli R and Faghihzadeh S. Preliminary Study of Puberty Education in Adolescent Girls :A Qualitative Research. 
Iranian Journal of Psychiatry and Clinical Psychology. 2003; 9: 64-70.

48. JalaliAria $\mathrm{K}$, Nahidi $\mathrm{F}$, AmirAliAkbari $\mathrm{S}$ and AlaviMajd H. Parents and teachers' view on appropriate time and method for female reproductive health education. Jornal of Gorgan University of Medical science (JGUMS). 2010; 12: 84-90[persian.[

49. Zare M, MalekA Afzali H, Jandghi J, Alammeh M, Kolahdoz $M$ and Asadi O. Effect of training regarding puberty on knowledge, attitude and practice of 12-14 year old girls .Journal of Guilan University of Medical Sciences. 2006; 14: 18 - 26.

50. Scirven A and Orme J. Health promotion: professional. Perspective palgrave. Mac Milan Press, 1996.
51. Srikala B and Kumar KK. Empowering adolescents with life skills education in schools-School mental health program: Does it work? Indian Journal of psychiatry. 2010; 52: 344.

52. Duffy B, Fotinatos N, Smith A and Burke J. Puberty, health and sexual education in Australian regional primary schools: Year 5 and 6 teacher perceptions. Sex Education. 2013; 13: 186-203.

53. Tylee A, Haller DM, Graham T, Churchill R and Sanci LA. Youth-friendly primary-care services: how are we doing and what more needs to be done? The Lancet. 2007; 369: 1565-73.

54. Senderowitz J. Making reproductive health services youth friendly. FOCUS on young adults, 1999. 